\title{
Functional Glycopolypeptides: Synthesis and Biomedical Applications
}

\author{
Zhao Wang $\mathbb{D}^{1}{ }^{1}$ Xiaojuan Zhang, ${ }^{1}$ Qing Lin, ${ }^{1}$ Jingjing Sun, ${ }^{2}$ Santanu Bhattachaya $\mathbb{D},{ }^{3}$ \\ Guosong Chen $\mathbb{D}^{4},{ }^{4}$ and Ruilong Sheng $\mathbb{D I}^{5}$ \\ ${ }^{1}$ School of Material Engineering, Jinling Institute of Technology, Nanjing 211169, China \\ ${ }^{2}$ Center for Pharmacogenetics, Department of Pharmaceutical Sciences, School of Pharmacy, University of Pittsburgh, Pittsburgh, \\ PA 15261, USA \\ ${ }^{3}$ Departments of Organic Chemistry, Indian Institute of Science, Bangalore 560012, India \\ ${ }^{4}$ The State Key Laboratory of Molecular Engineering of Polymers and Department of Macromolecular Science, Fudan University, \\ Shanghai 200433, China \\ ${ }^{5}$ CQM-Centro de Química da Madeira, Universidade da Madeira, Campus da Penteada, 9000-390 Funchal, Portugal
}

Correspondence should be addressed to Guosong Chen; guosong@fudan.edu.cn and Ruilong Sheng; ruilong.sheng@staff.uma.pt

Received 11 July 2019; Revised 22 February 2020; Accepted 27 March 2020; Published 2 June 2020

Academic Editor: Alain Durand

Copyright (c) 2020 Zhao Wang et al. This is an open access article distributed under the Creative Commons Attribution License, which permits unrestricted use, distribution, and reproduction in any medium, provided the original work is properly cited.

\begin{abstract}
Employing natural-based renewable sugar and saccharide resources to construct functional biopolymer mimics is a promising research frontier for green chemistry and sustainable biotechnology. As the mimics/analogues of natural glycoproteins, synthetic glycopolypeptides attracted great attention in the field of biomaterials and nanobiotechnology. This review describes the synthetic strategies and methods of glycopolypeptides and their analogues, the functional self-assemblies of the synthesized glycopolypeptides, and their biological applications such as biomolecular recognition, drug/gene delivery, and cell adhesion and targeting, as well as cell culture and tissue engineering. Future outlook of the synthetic glycopolypeptides was also discussed.
\end{abstract}

\section{Introduction}

Carbohydrates play a critical role in a large number of biological processes like metabolism, signal transduction, adhesion, and recognition. Early studies disclosed that many natural glycoconjugates are important messaging molecules, playing vital roles in many physiological and pathological processes by effective transmission of biological information/signals through specific recognition with proteins [1]. Among them, glycopolymers, as synthetic polymeric compounds containing pendant glycosides [2], have attracted growing attention and demonstrated wide applications as powerful tools for carbohydrate-lectin interaction research, as well as acting as scaffolds for tissue engineering and drug carriers [3-5]. They are usually produced by controlled radical polymerization (e.g., Reversible Addition-Fragmentation Chain Transfer Polymerization (RAFT) or Atom Transfer Radical Polymerization (ATRP)) of vinyl monomers and ring-opening metathesis polymerization of norbornenes [6-8]. Hence, it is easy to control the composition, chain length, carbohydrate density, and topology of glycopolymers, which are the key factors determining precise recognition for carbohydrate and lectin $[3,6,8,9]$, while the backbones of glycopolymers are carbon chains, which are nonbiodegradable and have no other biological functions other than to serve as spacer units.

In contrast, the polyamino acids/polypeptides are biocompatible and biodegradable and have the intriguing ability to fold into secondary structures such as an $\alpha$-helix and a $\beta$ sheet due to multiple noncovalent interactions. The intrinsic secondary structures are favorable for self-assembled aggregate formation with various shapes/morphologies, such as spherical/cylindrical/fibrous micelles, vesicles, and hierarchical structures $[10,11]$. Naturally occurring glycosylated peptides or proteins, donated as glycoproteins, reveal a wide range of biological functions such as antifreezing, mediation of cellular recognition, adhesion, proliferation of cells, cancer 
cell metastasis, and inflammatory reactions $[12,13]$, while the artificial synthesis of natural glycoproteins is hard to accomplish, which hinders their further applications.

Glycopolypeptides are generally referred to as polyamino acids/polypeptides containing pendant sugar moieties. Sometimes glycopeptide analogues, such as chemical conjugates of polyamino acids/polypeptides with natural polysaccharides or glycopolymers with various topologies such as linear and dendritic, are also referred to glycopolypeptides [14]. As a synthetic analogue of natural glycoprotein, the glycopolypeptide not only is expected to have biological properties of glycoproteins but also has the advantages of well-defined and comparatively regular structures and facile preparation, much easier for scaleup production, compared with glycoprotein $[15,16]$. The researches on synthetic glycopolypeptides benefit understanding the physicochemical properties and biological properties of natural glycoproteins and provide a model for the study of the structure-activity relationship (SAR) between the structures of glycoprotein and their physicochemical/biological functions. Meanwhile, coupling carbohydrate units to side chains or termini of the polyamino acid can bring about not only good hydrophilicity-specific biomolecular recognition, as well as cell adhesion characteristics, but also better biodegradability and interesting selfassembly morphologies compared with glycopolymers, which guarantee their wide applications as therapeutic gene/drug delivery vehicles.

Though synthetic glycopolypeptides have been known for over 20 years [17], the production of glycopolypeptides in larger quantities with controllable structures is still a challenging task. The understanding of their hierarchical assembly and lectin recognition and their applications as biomedical materials are still in their infancy. In this review, we summarize the state of the art in the design and synthesis of glycopolypeptide and their analogues via three different synthetic strategies, their biomimetic selfassembly behavior and lectin recognition character, and their biomedical applications as drug/gene delivery vehicles, tissue engineering scaffolds, antimicrobial agents, etc. Finally, we briefly look at the future development of the synthetic glycopolypeptides.

\section{Synthesis of Glycopolypeptides}

In general, three different methodologies are applied for the synthesis of glycopolypeptides (Figure 1). The first synthetic method is postpolymerization glycosylation of synthetic polypeptides, which involves preparation of functional polypeptide backbones via ring-opening polymerization (ROP) of $\alpha$-amino acid-N-carboxyanhydrides (NCAs) and continuous postpolymerization modification (via activated ester coupling, isothiocyanate linking, "click" chemistry, methionine alkylation, etc.) to introduce the carbohydrate residues. The second synthetic method is polymerization of glycosylated NCA monomers (glyco-NCAs) via ROP in a controlled manner, in which synthesis and purification of glyco-NCAs is the key point and is hard to manipulate. In addition, as an alternative pathway, terminus-glycosylation can also introduce saccharide units (monosaccharides, oligosaccharides, polysaccharides, or glycopolymers) to the terminal functional group of a polypeptide backbone, which can take advantage of the ROP process of regular NCA monomers and high efficient coupling reactions.

2.1. Glycosylation of Synthetic Polypeptides. Synthetic polypeptides/polyamino acids, as the synthetic analogues of natural proteins or peptides, have received increasing attention as biomaterials in the past few decades, due to their abundant biomedical applications including drug delivery, gene therapy, antibiotics, and tissue engineering [18]. The most favorite route to synthesize polypeptides is the ring-opening polymerization (ROP) of NCAs, a type of monomer usually prepared by phosgenation of side chain-protected $\alpha$-amino acids, initiated by nucleophiles (primary amines) or bases (tertiary amines and alkyl oxides) (Scheme 1) [19]. Until now, nearly 200 different natural or unnatural NCA monomers have been synthesized for polypeptide preparation, and much progress has been made in the development of new initiators and reactions to achieve controlled NCA polymerizations $[11,18,20,21]$.

"Click" chemistry has been proven to be highly efficient due to its mild reaction conditions, high efficiency, good adaptivity to functional groups, and easy purification of products [22-24]. The typical "click" chemistry involved $\mathrm{Cu}$ (I)-catalyzed azide-alkyne [3+2] cycloaddition (CuAAC), strain-promoted cycloaddition of alkynes and azides (SPAAC), Diels-Alder reaction, and thiol-involved reactions (Figure 2). The progress of "click" reactions largely promotes the synthesis of glycopolypeptides. The well-known CuAAC reaction has been firstly and widely used in the preparation of glycopolypeptides. Xiao and coworkers [25] firstly prepared poly $(\gamma$-propargyl-L-glutamate) (PPLG) via ROP of the $\gamma$ propargyl-L-glutamate NCA monomer, which was synthesized by the acid-catalyzed esterification of L-glutamic acid with propargyl alcohol, and coupled the resulting polypeptide to three different azide-functionalized monosaccharides by the CuAAC method (Scheme 2). The coupling reaction was found to proceed with near complete conversion, yielding glycopolypeptides with high sugar densities. After that, Borase et al. [26], Kapetanakis and Heise [27], and Dhaware et al. [28] reported a functional glycopolypeptide complex with either molecular recognition, thermo-responsive, or magnetic resonance imaging (MRI) character in a related strategy. Nevertheless, the potential limitation of the method is the ester hydrolysis of PPLG side chains in biological environments, leading to reduced activity over time. To address this issue, Heise and Lecommandoux [29-31] synthesized some galactosylated polypropargylglycine (PGG) homopolymer and $\operatorname{poly}(\gamma$-benzyl-L-glutamate)-block-(glyco-polypropargylglycine) (PBLG- $b$-PGG) block copolymer via the CuAAC approach, by using hydrolytically stable clickable side-chain moieties.

Similarly, synthesis of polypeptides with an azidefunctionalized pendent, following the couple with alkynylcontaining saccharides via CuAAC, is an alternatively approach. Tang and Zhang [32] first synthesized a $\gamma$-chloropropyl-L-glutamate-NCA by the monoesterification of 


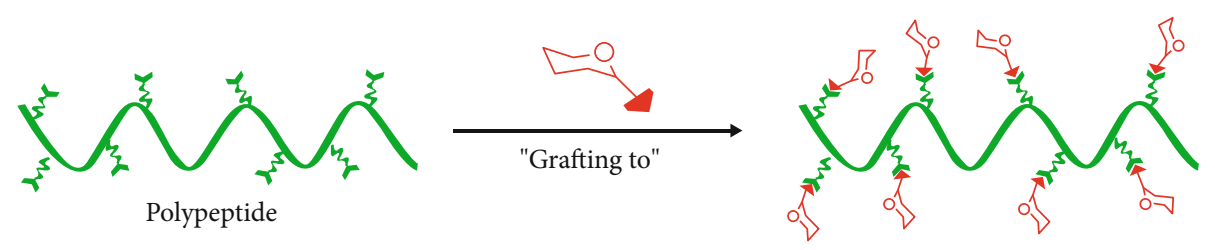

(a)
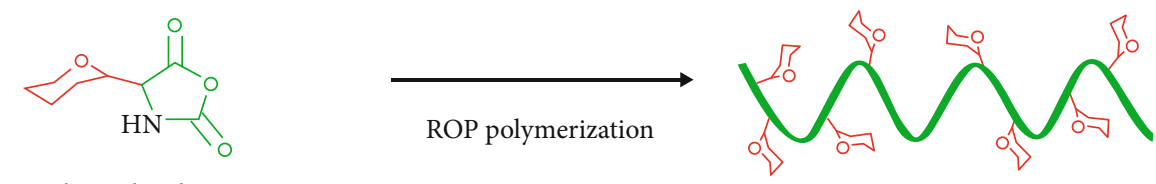

Glycosylated NCA

(b)

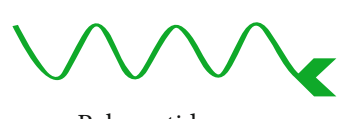

Polypeptide

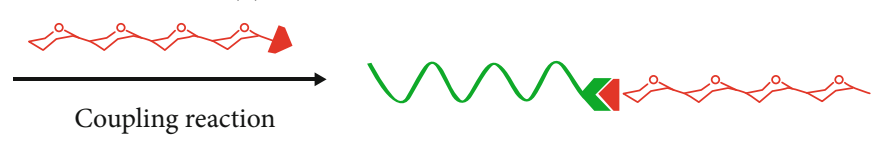

(c)

Figure 1: A general representation of synthetic strategies of glycopolypeptides by (a) postpolymerization glycosylation of synthetic polypeptides, (b) polymerization of glycosylated N-carboxyanhydrides (glycol-NCAs), and (c) glycosylation at the terminus group of a polypeptide.

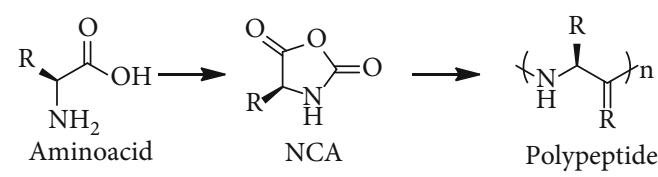

SCHeme 1: Synthesis of polypeptides via ROP of NCA.

glutamic acid with 3-chloropropyl alcohol in the presence of chlorotrimethylsilane. After polymerization and azidation via sodium azide, the obtained polypeptides were allowed the quantitative addition of 1-propargyl- $\alpha$-D-mannose via CuAAC. Then, Rhodes and Deming [33] prepared two other kinds of azide-containing NCA monomers in one step from $N_{\alpha}$-carboxybenzyl-L-ornithine and $N_{\alpha}$-carboxybenzyl-Llysine, respectively. By ROP of these NCA monomers, they obtained homo and diblock azidopolypeptides with controlled segment lengths, which were to be further coupled with alkynyl-containing saccharides via CuAAC reaction to yield hydrolytically stable glycopolypeptides.

Besides, clickable polypeptides based on thiol-yne/ene reaction were developed by Schlaad and coworkers [34-36]. They prepared poly(D/L-allylglycine) from the NCA of commercially available racemic allylglycine. Radical thiol-ene additions were further performed with 2,3,4,6-tetra-O-acetyl-1-thio- $\beta$-D-glucopyranose and quantitatively achieved glycopolypeptides (Scheme 3 ). Another alternative approach based on the alkylation of methionine residues was described by Kramer and Deming [37, 38] in 2012. Well-defined and fully glycosylated polypeptides were readily prepared with high yield by alkylation of poly(L-methionine) with a triflate(-OTf-) or iodo- (-I-) substituted glycoside.

Up to now, nearly 10 types of polypeptides with clickable pendent groups have been developed. Their structures and corresponding grafting saccharide units could be found in Table 1 [25-40]. By this "grafting to" approach, the grafting efficiency of sugar-containing moieties largely depends on the key factors such as molecular hydrophobicity/hydrophilicity, steric hindrance, reaction mediums, and catalysts, which still remain challenges to be addressed. Enriching new types of clickable polypeptides, simplifying the synthesis steps, and improving the efficiency of the grafting modification are the focus of current research.

2.2. Polymerization of Glyco-NCAs via Ring-Opening Polymerization (ROP). Rüde et al. [41] first synthesized the $O$-linked glycosylated-serine (glyco-ser) NCAs in 1966, and Tsutsumiuchi et al. [42] described the first synthesized welldefined glycopolypeptide with number-average molar mass $\left(M_{\mathrm{n}}\right)$ of about $10 \mathrm{~kg} \mathrm{~mol}^{-1}$ and polydispersity $M_{\mathrm{w}} / M_{\mathrm{n}} \approx$ 1.1 , initiated by primary amine initiators, while high molecular weight glycopolypeptide was difficult to obtain, since this was limited by the purity of glyco-NCAs. Since then, although there have been reports on the synthesis methods of glyco-NCA monomers, the purity problem has not been effectively solved. Until 2010, Kramer and Deming [43] reported a flash chromatography method for the preparation of glycosylated-lysine NCAs for the first time, which solved the low purity of NCA monomers and achieved high molar mass $\left(M_{\mathrm{n}} \approx 160 \mathrm{~kg} \mathrm{~mol}^{-1}\right)$ glycopolypeptides with low dispersity.

The method for preparing a glycopolypeptide by NCA ring-opening polymerization of a sugar-containing NCA monomer can effectively avoid the problem of incomplete grafting reaction caused by postpolymerization modification, but the preparation and purification of the sugar-containing NCA monomer is difficult. Up to now, several synthetically challenging NCA monomers were elegantly synthesized and polymerized to yield glycopolypeptides bearing various carbohydrates. The specific structures are shown in Scheme 4 [17, 43-54]. Therefore, developing efficient and easy-to- 


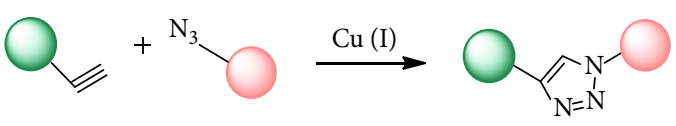

(a)

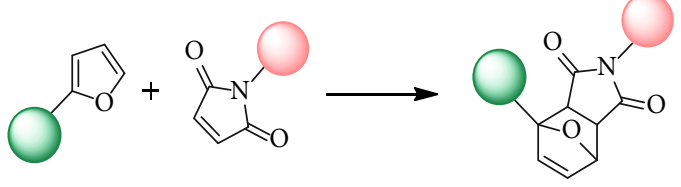

(c)

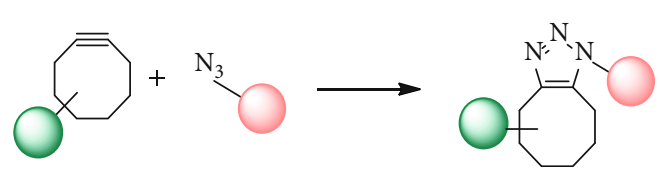

(b)

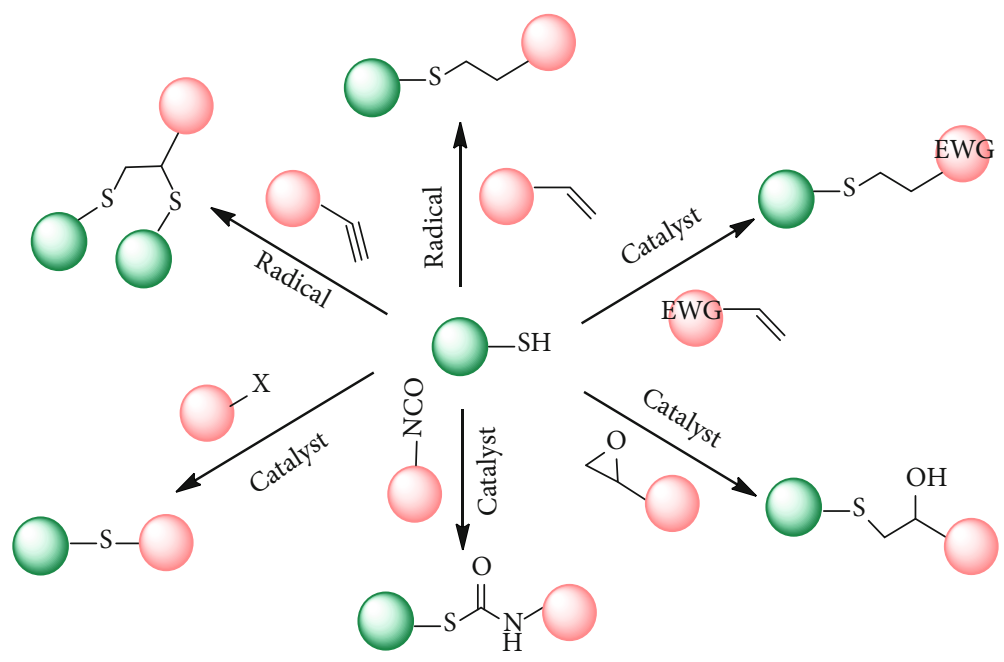

(d)

FIgURE 2: Schematic illustrations of the typical "click" reactions: (a) $\mathrm{Cu}$ (I)-catalyzed cycloaddition of alkynes and azides (CuAAC), (b) strainpromoted cycloaddition of alkynes and azides (SPAAC), (c) Diels-Alder reaction, and (d) thiol-involved reactions.

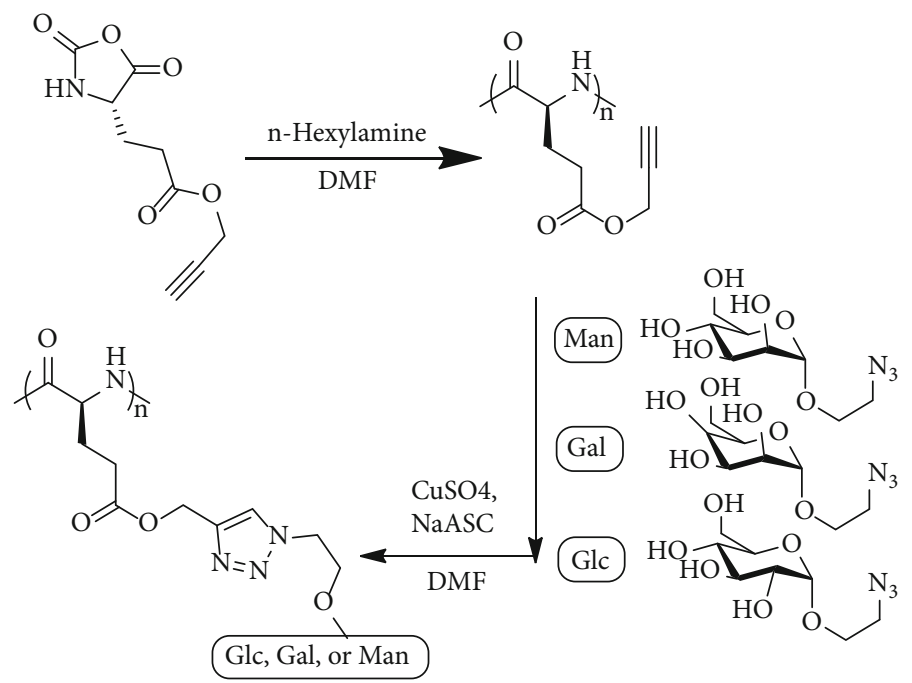

Scheme 2: CuAAC "click" glycosylation of poly( $\gamma$-propargyl-L-glutamate) by Xiao et al. [25].

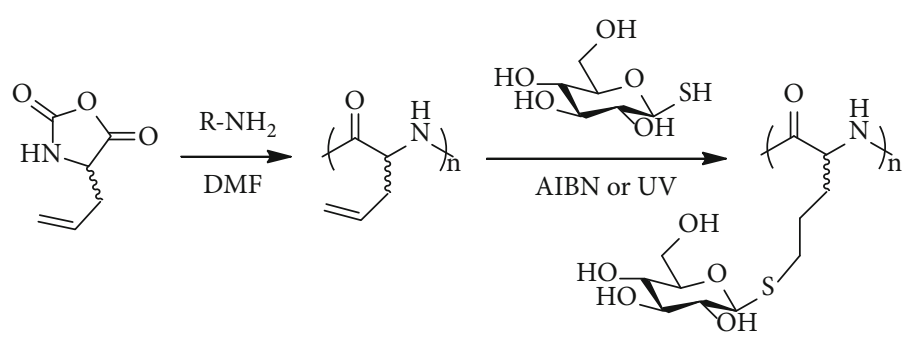

Scheme 3: Ring-opening polymerization of D/L-allyglycine NCA and postglycosylation via thiol-ene "click" glycosylation by Sun and Schlaad [34]. 
TABLE 1: Clickable polypeptides and corresponding saccharide units for the synthesis of glycopolypeptides.

\begin{tabular}{lll}
\hline Polypeptides & Saccharide units & Ref. \\
\hline [25-28]
\end{tabular}<smiles>C=CC(NC)C(C)=O</smiles><smiles>[R]OC1COCC1[N+]([NH-])=O</smiles><smiles>C=CC(=O)NCCCCC(NC)C(C)=O</smiles><smiles>[R]O[C]1CO[C@@H]([NH3+])C1</smiles><smiles>CCNC(CCC(=O)OCCCN)C(C)=O</smiles><smiles>[R]O[C]1CO[C@@H](C#C)C1</smiles><smiles>CNC(CCCN)C(C)=O</smiles><smiles>C#C[C@@H]1C[R]OC1</smiles><smiles>CNC(CCCCN)C(C)=O</smiles><smiles>C#C[C@H]1CO[R](C)C1</smiles><smiles>CC(=O)C1CC(=O)OCCN1</smiles><smiles>C#C[C@H]1C[C@@H](O)CO1</smiles><smiles>CC(=O)C1CC=CCN1</smiles><smiles>[R]O[C]1CO[C@@H](S)C1</smiles><smiles>C#CCC(NC)C(C)=O</smiles>

TABle 1: Continued.

\begin{tabular}{lll}
\hline Polypeptides & Saccharide units & Ref. \\
\hline
\end{tabular}

operate organic/polymer synthetic methods (e.g. "one-pot" glycosylation) to prepare stable glycol-NCA monomers with proper protection moieties and expanding the moieties' diversity need to be highly focused in future research.

2.3. Glycosylation at the Terminus Group of a Polypeptide Backbone. In order to overcome the cumbersome steps in the preparation of the above two glycan peptides, the difficulty of purification, the limited variety of monomers, etc., in recent years, researchers have attempted to couple glycosides to the terminus group of polyamino acid/polypeptide chains by highly efficient coupling reaction, e.g., "click" reaction. By these means, natural monosaccharide, disaccharide [55], oligosaccharide, polysaccharide [56-58], and synthetic glycopolymers [59] can be effectively coupled to the end of polypeptide chains to prepare linear, branched, and polymers with different topologies. These richly structured glycopolypeptide analogues provide a new approach to the study of glycomics and the diagnosis and treatment of diseases. At the same time, the structure and composition of the synthetic amphiphilic polypeptide analogues are more likely to regulate the hydrophilic/hydrophobic ratio and physicochemical properties of the polymer, which is beneficial to further regulate the formation of spherical, fibrous, and worm-like micelles and vesicle self-assemblies.

In the similar way, Lecommandoux et al. [56, 58, 60-63] initially introduced different oligosaccharides or polysaccharides to the end of the polypeptide by using copper-catalyzed Huisgen cycloadditions with an azido end-functionalized PBLG. In an aqueous solution, the resulting amphiphilic copolymers were able to self-assemble into glycosylated polymersomes with similar structures to viral capsids. In addition, the $\alpha$-helical structure of the PBLG favors the formation of lamellar morphologies, and the hyaluronic acid displayed at the surface of nanoparticles can target specifically cancer cells overexpressing the CD44 receptor.

Wang et al. [59] prepared a series of amphiphilic block copolymers (PMAgala-SS-PBLG) containing PBLG hydrophobic blocks and pendant hydrophilic galactosyl units by the combination of RAFT polymerization, NCA ringopening polymerization, and "click" coupling reaction. First, a RAFT chain transfer agent containing a disulfide bond and a terminal azide-functionalized group was prepared, and acetone-protected galactose monomer MAIpGP was polymerized to prepare an azide-functionalized glycopolymer precursor, which coupled with a terminal alkynyl functionalized PBLG block via a CuAAC reaction, followed by removing the galactose protecting group to obtain amphiphilic glycopolypeptide. The synthetic strategy 

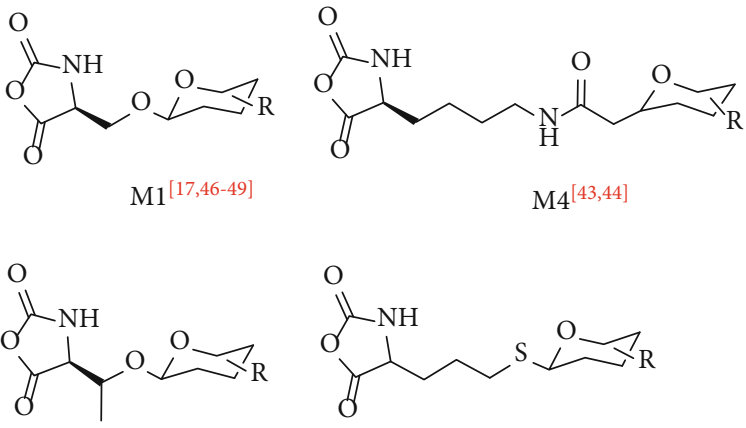

$\mathrm{M} 2^{[45]}$<smiles>[R]C1CCC(SC[C@H]2NC(=O)OC2=O)O1</smiles>

$\mathrm{M3}^{[45]}$<smiles>O=C1NC(CCCSC2CC3CCCC2O3)C(=O)O1</smiles><smiles>O=C1NC(CCCCNC(=S)NCCOCCOC2CC3CCC(C2)O3)C(=O)O1</smiles>

M6 ${ }^{[52]}$<smiles>[R]C1CCC(OC(=O)NCCCC[C@@H]2NC(=O)OC2=O)OC1</smiles><smiles>[R]C1CCC(CCCSCC[C@H]2NC(=O)OC2=O)OC1</smiles>

SCHEME 4: Chemical structures of sugar-substituted NCA monomers.

can effectively regulate the length of the glycopolymer and polypeptide blocks. The galactose block brings about the liver tumor cells' HepG2-targeting effects; the $\alpha$-helical structure of polypeptide could offer a biocompatible, hydrophobic core and regular motifs/template for selfassembly; and the introduction of an interfacial disulfide bond can realize the reductive responsive drug release features (Figure 3).

It has been revealed that the topology of the molecular architecture is a basic factor determining the self-assembly behavior of polymers in the solution. Copolymers with complex topologies, including random, block, graft, cyclic, dendrimer-like, and hyperbranched polymers, displayed diverse self-assembly behavior in selective solvents [64-66]. Synthesis of glycopolypeptides with various topologies and defined chemical compositions is a daunting task, while end-coupling strategies of saccharide units with polypeptides provided an achievable pathway to prepare a rich variety of glycopolypeptide analogues with interesting topological architectures. Bonduelle and coworkers [67] designed a tree-like glycopolypeptide by using a poly(g-benzyl-L-glutamate)-block-poly(DL-propargylglycine) (PBLG- $b$-PPAG P $_{5}$ scaffold onto which was efficiently grafted dextran by "click" reaction (Figure 4). Wali et al. [68] prepared lactosylated pullulan-graft-arginine dendrons (LP-g-G3P) by CuAAC cycloaddition between hydrophilic lactosylated pullulan and hydrophobic $3^{\text {rd }}$-generation- $\left(\mathrm{G}_{3^{-}}\right)$arginine dendrons bearing Pbf and Boc groups on the periphery. Fu et al. [69] synthesized a pH-responsive amphiphilic multiblock copolymer by RAFT polymerization, NCA ring-opening polymerization, and "click" coupling combination strategy, followed by grafting anticancer drug DOX and nearinfrared fluorescence (NIR) probe via an amide bond and hydrazone, respectively, to obtain a theranostic polymeric prodrug. In addition, using a similar multiple reaction combination strategy, four-arm star glycopolymer-polypeptide conjugates $\mathrm{P}($ GlyEMA)-P(lys) were also prepared [70].

\section{Biomimetic Self- Assembly of Glycopolypeptides}

For biomedical-related applications such as drug/gene delivery vehicles or a biomimetic structure, it is essential to control the morphology, structure, and functionality of glycopolypeptide self-assemblies. A key feature of the glycopolypeptide is that the polyamino acid skeleton can adopt well-defined stable secondary structures such as the $\alpha$-helix, $\beta$-sheet, or random coil, depending on their intrinsic molecular structures or external environment (temperature, solution $\mathrm{pH}$, ionic strength, etc.) [71]. From this point of view, glycopolypeptides could self-assemble into aggregates with various interesting morphologies, with the ability to fold into well-defined secondary structures. Meanwhile, previous studies have revealed the structure transition of the glycopolypeptide in response to external stimulus, such as $\mathrm{pH}[35,36]$, ionic [72], or reducing environment [53]. Furthermore1, because polypeptides are chiral polymers, chirality should be another distinctive factor influencing the self-assembly behaviors and functions of the formed structures [73, 74]. On the other hand, the assembly constructed from the glycopolypeptide with an outer saccharide shell can mimic natural glycocalyx on the surface of the cell/virus, promoting the wide exploration and applications of glycopolypeptide-based selfassembly systems.

Lecommandoux et al. [30, 31, 56, 58, 60] synthesized a series of oligosaccharide-block-PBLG conjugates via $\mathrm{CuAAC}$ reaction. It was found that the $\alpha$-helical structure of the polypeptide favors the formation of lamellar morphologies and could self-assemble into a vesicle assembly in an aqueous solution with the "viral capsid-like" structure. The amphiphilic polypeptide (PBLG- $b$-PGG) in which a hydrophilic block galactosylated propargylglycine (PGG) coupled with a hydrophobic PBLG is able to selfassemble into micelle, vesicle, or worm-like aggregates in 


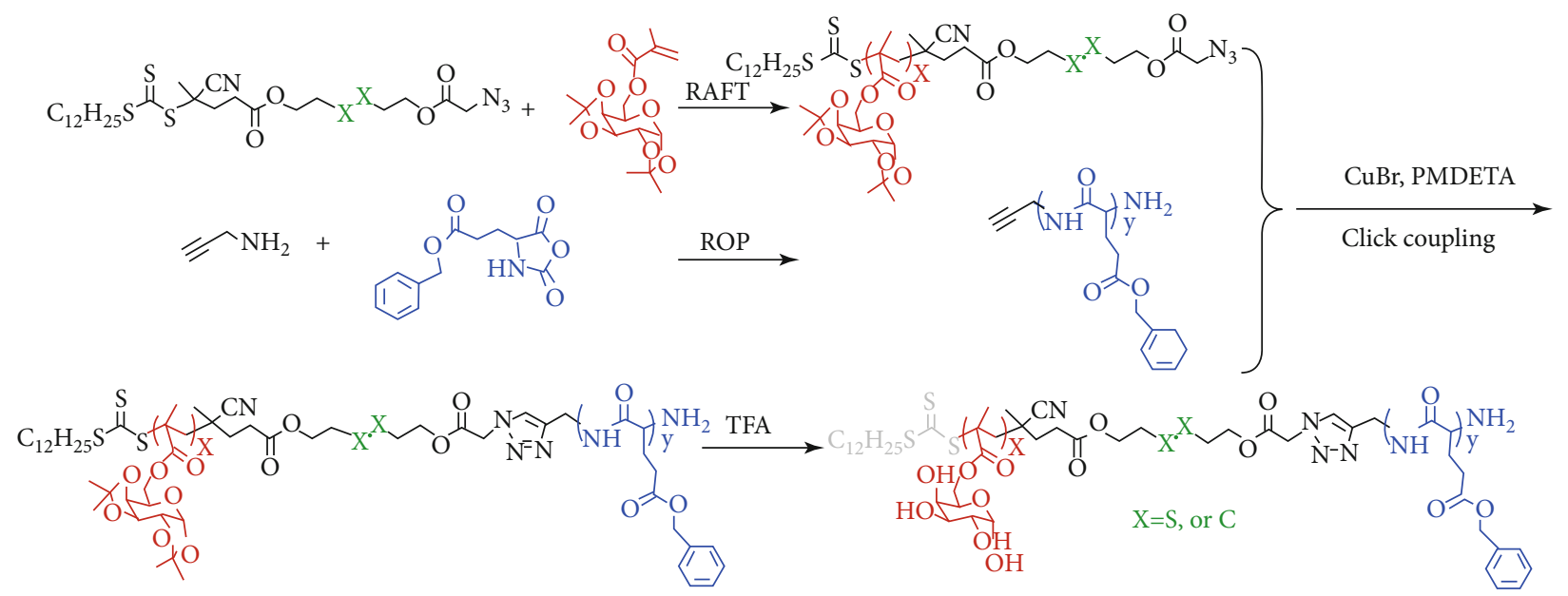

(a)

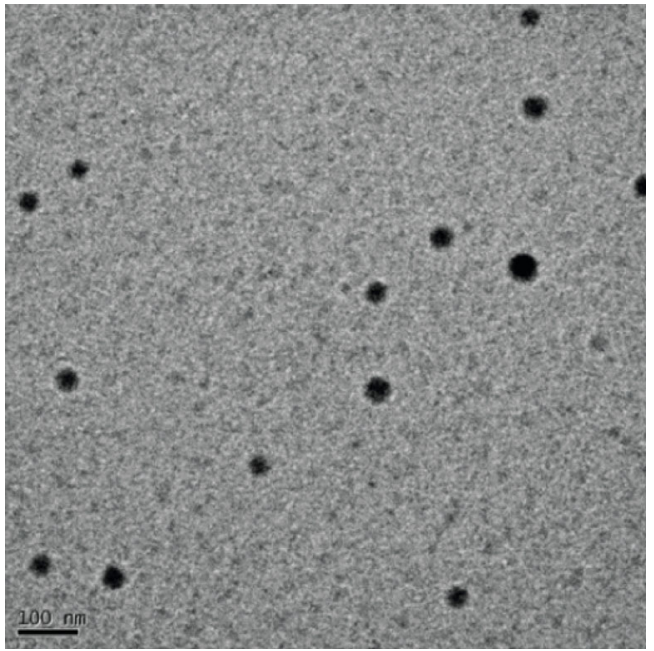

(b)
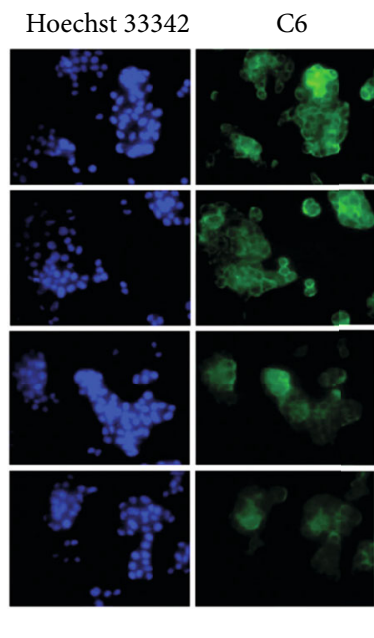

Merge Galactose
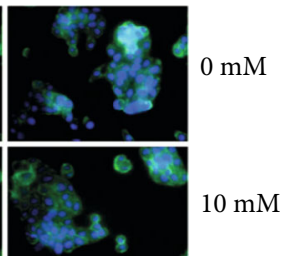

(c)

FIGURE 3: (a) Schematic pathways for the preparation of glycopolypeptide analogues via a combination of RAFT polymerization, NCA ringopening polymerization, and "click" coupling reaction; (b) TEM images for the PMAgala $27-S S-$ PBLG $_{30}$ self-assembled micelles; (c) galactose competitive inhibition experiments to show HepG2-targeting effects. Fluorescence microscopic images (400x) of HepG2 cells were pretreated with C6-loaded micelles $(100 \mu \mathrm{g} / \mathrm{mL})$ under galactose of various concentrations.

an aqueous solution. The morphologies were dependent on the hydrophilic/hydrophobic block ratios, and different morphological aggregates can specifically recognize the lectin $\mathrm{RCA}_{120}$. Kramer et al. [75] studied the effect of the secondary structure of the glycopolypeptide polymer on the self-assembly and found that if the hydrophilic glycopolypeptide block has a random structure, it selfassembled into a vesicle structure aggregate, while $\alpha$ helix-structured glycopolypeptides induced the formation of sheet-like assemblies (Figure 5).

Most recently, to mimic the diverse glyco-conjugate structures in nature, Liu et al. [76] designed and synthesized a series of well-defined amphiphilic glycopolypeptide brushes (AAGBs) with pendent glycodendrons (to guarantee a very high density of sugar units) and $\beta$-sheet-forming oligopeptide (to provide the driving force for resembling the natural assembly process) (Figure 6). They self-assembled into various morphologies, including nano- wires, nanoribbon, nanovesicles, and nanomicelles, depending on the ratio of the sugar units to the amino acid species. Notably, the glycopolypeptides went through a series of successive self-assembly processes and showed interesting hierarchical self-assembly features, including micellization, micelle alignment-forming nanofilaments, branching of the nanofilaments by micelles, and finally nanowire formation by micelle fusion. This was the first reported example of hierarchical self-assembly by glycopolypeptide, which will pave a new way to biomimic the structure of natural glycoproteins.

Interesting self-assembly behavior on glycopolypeptidehybrid copolymers also achieved great attention. Pati et al. [77] described the self-assembly of amphiphilic glycopolypeptide-dendron block copolymers of glycosylated poly(L-lysine) attached to an aromatic dendron of generation 1 or 2. Either nanorods or nanomicellar aggregates were achieved in the aqueous solution, and the 

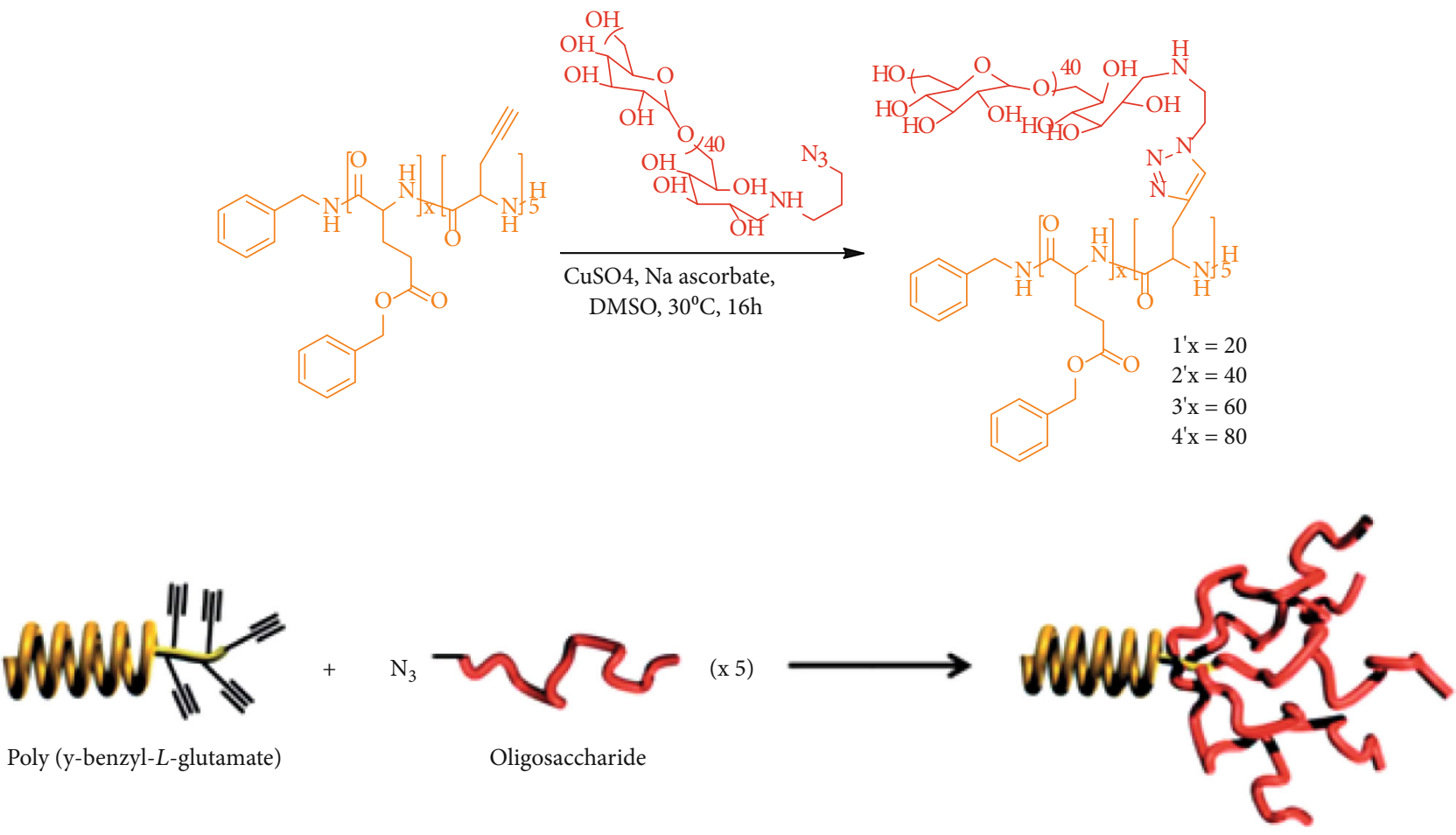

FIGURE 4: Synthesis of oligosaccharide-based tree-like glycopolypeptide PBLG- $b$-PPAG 5 by Lecommandoux et al.

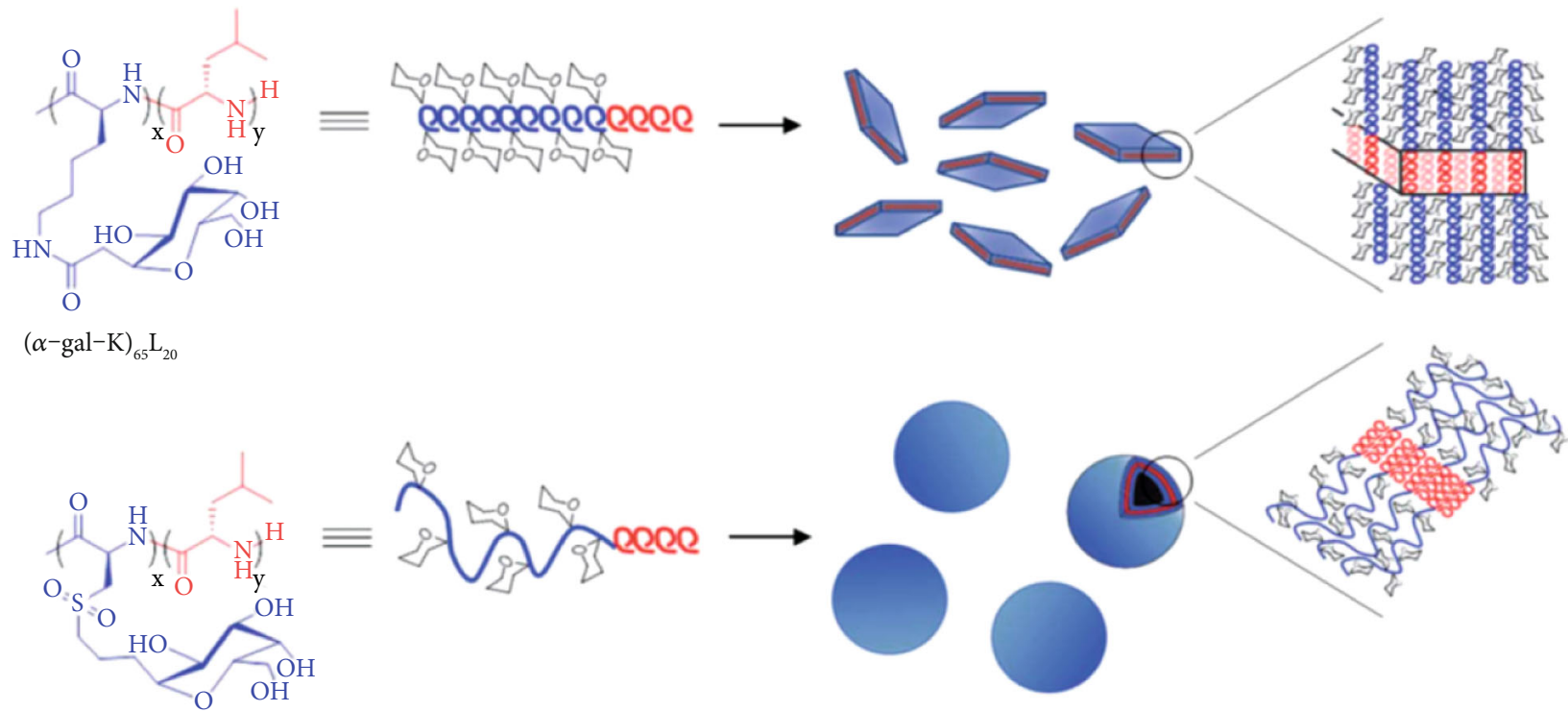

$\left(\alpha-\mathrm{gal}^{-} \mathrm{C}^{02}\right)_{65} \mathrm{~L}_{20}$

FIGURE 5: Schematic showing structures of amphiphilic glycosylated diblock copolypeptides and observed self-assemblies (reprinted with permission from Ref. [75]; copyright (2013) Royal Society of Chemistry).

cooperation effects of chain segregation and $\pi-\pi$ stacking of the dendrons will be applied to explain the selfassembly behavior. After that, glycopolypeptide- $b$-poly(propylene oxide) was designed, and the presence of an ordered helical glycopolypeptide segment is required for their self-assembly into spherical nanoscale $(\approx 50 \mathrm{~nm})$ polymersomes [78]. In addition, miktoarm star copolymers comprising glycopolypeptide and poly(e-caprolactone) chains using ring-opening polymerization and "click" chemistry were also prepared by the same research group, and it is found that self-assembled morphologies such as nanorods, polymersomes, and micelles could be tuned by chain length of the blocks and were not affected by the type of sugar residue [79]. 


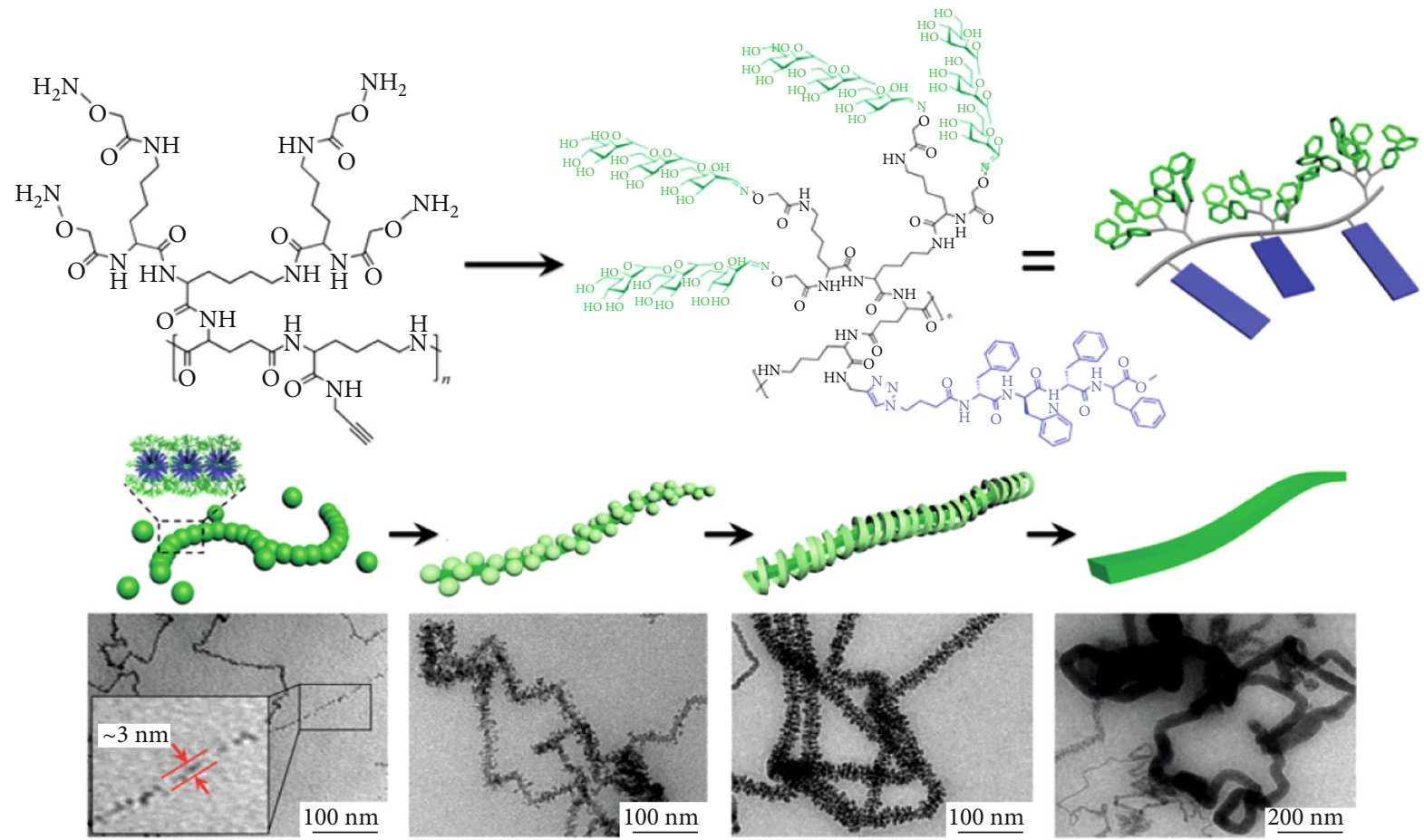

Hierarchical self-assembly

FIGURE 6: Synthesis and chemical structure of alternating amphiphilic glycopolypeptide brushes (AAGB) with glycodendron and oligopeptide pendants and their schematic illustration as well as TEM images of the hierarchical self-assembly process (reprinted with permission from Ref. [76]; copyright (2016) American Chemical Society).

\section{Biological Applications of Synthetic Glycopolypeptides}

Carbohydrate-containing macromolecules have always been a hot research topic due to their central roles in biological communication events, such as cellular recognition, signal transmission, inflammation, and infection of pathogens. Many studies have shown that recognition, often based on specific carbohydrate-lectin interactions which occurred on the surface of cells, is the first step in numerous biological processes which relied on cell-cell interactions. Lectins bind specifically but weakly to carbohydrates; however, the binding effect turns out to be much stronger when these signal carbohydrate molecules are arranged along a polymer backbone or any other entity, which is termed the "glycocluster effect" [80]. So, glycopolymers or glycopolypeptides with abundant grafting carbohydrate functional groups have the ability to produce multivalent interactions with the lectins. Researches revealed that the lectin Ricinus communis agglutinin II $\left(\mathrm{RCA}_{120}\right)$ could specifically bind galactosyl residues, and Concanavalin A from Canavalia ensiformis (ConA) exhibited high affinity to the glucosyl and mannosyl residues [81]. The binding effect was largely enhanced when carbohydrates grafted onto the polypeptide backbone to form the glycopolypeptide due to the so-called "multivalent effect." Nevertheless, the mechanisms and influence of the ligand structural factors (e.g., polymer topological structure, carbohydrate density, and morphology of 3D glycol nanoparticles) on the multivalent effect were still very unclear $[8,82,83]$. The deep research on the specific interaction between lectin and glycopolypeptide will be helpful to develop new biomaterials with specific biorecognition properties.

Some instrumental analyses such as turbidity assays, surface plasmon resonance (SPR), and isothermal titration calorimetry (ITC) have been carried out to elucidate the recognition and specific interaction of the synthetic glycopolypeptide with lectins. It is revealed that the degree of grafted sugar density affects the kinetics of lectin binding, and the higher sugar grafting density results in stronger binding capacity $[35,77,84]$. In addition, Byrne et al. [85] systematically studied the effect of primary architecture/topological morphology of glycopolypeptides on lectin binding efficiency. It was found that for multiple-arm glycopolypeptides with the same glycosylation degree, the more arms of the glycopolypeptide, the stronger the binding efficacy with ConA they showed. For series of starshaped glycopolypeptides prepared from poly(glutamic acid) with different molecular weights and different degrees of glycosylation, the binding efficiency is dependent on the polymer architecture and the degree of glycosylation. Generally, it was found that a higher content of glucosamine leads to faster ConA lectin binding [85]. Most recently, they newly synthesized a series of glycopolypeptides with identical overall composition and 
systematically varied sequences (statistical, diblock, tetrablock, and octablock) and found that the binding efficiency with lectin was dependent on the position of the galactose units and thus the primary glycopolypeptide structure. The octablock glycopolypeptide [(GA) $5^{-}$ $\left.(\mathrm{GalG})_{5}\right]_{4}$ adopted an $\alpha$-helical conformation and favored interaction with lectin $\mathrm{RCA}_{120}$, while the tetrablock glycopolypeptide $\left[(\mathrm{GA})_{10^{-}}(\mathrm{GalG})_{10}\right]_{2}$ adopted a random coil conformation and showed the strongest binding activity to Galectin-3 [86] (Figure 7). From this point of view, we can conclude that the lectin binding is very sensitive to glycocoding and can be controlled by the precise design of carbohydrate units and sequences in synthetic polymeric glycopolypeptides, which is very important to realize glycopolypeptide-based diagnosis and therapeutic systems towards precise biomedical applications.

Though saccharide-involved lectin recognition has been intensively studied for decades, researches of polymeric nanoparticles constructed by glycopolypeptides applied as gene/drug delivery have just been started $[56,60,69,79,87-90]$. It has been revealed that terminal $\beta$-D-galactose (Gal) or N-acetylgalactosamine (GalNAc) residues can be recognized by asialoglycoprotein receptor (ASGPR), a high-capacity C-type lectin receptor expressed on mammalian hepatocytes [91]. So, Gal/GalNAc-containing glycopolypeptides were considered as liver-targeted drug/gene carriers. In 2005, Sung et al. [92, 93] first designed poly(glutamic acid)-block-poly (lactic acid) (PGA-PLA) copolymers with galactose grafts which were applied in paclitaxel delivery to achieve efficient drug accumulation in tumors. Then, Ding et al. [89] used a glycopolypeptide as a DOX delivery carrier and demonstrated that the galactose-decorated nanomedicine showed much higher antitumor activity toward HepG2 cells compared to the nanomedicine without the galactosyl group in vitro and in vivo. As mentioned before, Fu et al. designed and conjugated a polymeric prodrug with a near-infrared region (NIR) probe to prepare glycopolypeptide theranostics, which showed a $\mathrm{pH}$-responsive DOX release, strong NIR fluorescence emission, and highly selective accumulation in liver cancer cells due to its ligand-ASGPR recognition process [69]. Most recently, a glycopolypeptide-based interface-crosslinked nanomicellar structure was designed and prepared. It was constructed by an amphiphilic miktoarm star copolymer, which contains a short DLpropargyl glycine block with pendent alkyne groups (for click-crosslinking at the core-shell interface) at the junction of the hydrophobic and hydrophilic arms. The micelles were stable up to 2-3 weeks and exhibited dual stimuli-responsive (redox- and enzyme-responsive) DOX release behavior, which paves a new way for the design and preparation of stable glycopolypeptide-based nanocarriers for redox/enzyme dual-stimuli-responsive delivery of drugs into cancer cells [90] (Figure 8).

Apart from the successful application of glycopolypeptides as nanocarriers towards drug/gene delivery, the application of glycopolypeptides in the field of cell and tissue engineering is relatively rare. Cheng et al. [94] synthesized poly(ethylene glycol)-block-poly( $\gamma$-propargyl-
L-glutamate)- (PEG-PPLG-) based thermosensitive hydrogels with galactose grafts. The hydrogels showed excellent cytocompatibilities and could promote cell adhesion. Afterward, they further designed a glycopolypeptide by conjugation of PPLG with azido-modified mannose and 3-(4-hydroxyphenyl) propanamide (HPPA), via "click" chemistry (Figure 9). The glycopolypeptide hydrogels were in situ formed by enzyme-catalyzed crosslinking reaction. In vitro $3 \mathrm{D}$ cell culture and a nude mouse subcutaneous model revealed that the crosslinked biomimetic glycopolypeptide hydrogels as a cartilaginous-specific matrix were beneficial to the survival and proliferation of chondrocytes. The results indicated that the biomimetic glycopolypeptide-based hydrogels may serve as threedimensional scaffolds for cartilage tissue engineering [95].

In addition to the aforementioned applications, glycopolypeptides also showed promising application in other biomedical fields. For example, Tachibana et al. and Artigas et al. $[96,97]$ developed efficient and versatile strategies to construct sequential tandem repeating glycopeptides by means of a combined chemical and enzymatic strategy. These mucin-like glycoprotein mimics could act as valuable macromolecular models for antifreeze glycoprotein. Yang et al. [40] prepared bioreducible amphiphilic block copolymers based on PCL and glycopolypeptide. The self-assembled spherical nanosized micelles can simultaneously load the anticancer drug DOX and superparamagnetic iron oxide (SPIO) nanoparticles. The responsive drug release and excellent magnetic resonance (MR) contrast enhancement enabled its theranostic potential as a nanocarrier for MR imaging and chemotherapy. Pranantyo et al. [70] synthesized a series of four-arm star copolymers, incorporating glycopolymer and antimicrobial poly-l-lysine domains. The glycopolymer-polypeptide conjugates were nonhemolytic, exhibited high cytocompatibility, and showed a broad spectrum of antimicrobial activity toward both Grampositive and Gram-negative bacteria. Moreover, the pendant mannose moieties of the conjugates also increased microbial targeting due to their specific affinity for bacterial surfaces, which gives a new concept in the design of glycopolypeptide-based antimicrobial agents to combat infectious disease.

\section{Summary and Outlook}

In summary, the synthesis strategy and biomedical applications of glycopolypeptides is an important frontier research area in the fields of polymer chemistry, material science, and biomedicine. Biologically, developing synthesized glycopolypeptides is an in-depth study of the structure and function of glycoproteins/peptides, to eventually achieve biomimetic modeling of natural structural glycoproteins/peptides (such as glycocalyx, transporters, collagen, and keratin) in an artificial approach. Most of the research works on the synthesis of glycopolypeptides has been published since 2010, and its application in biomedicine has just stayed at the beginning level. There are still a lot of unknown and challenging areas to be explored. For example, using glycopolypeptides to identify, detect, 


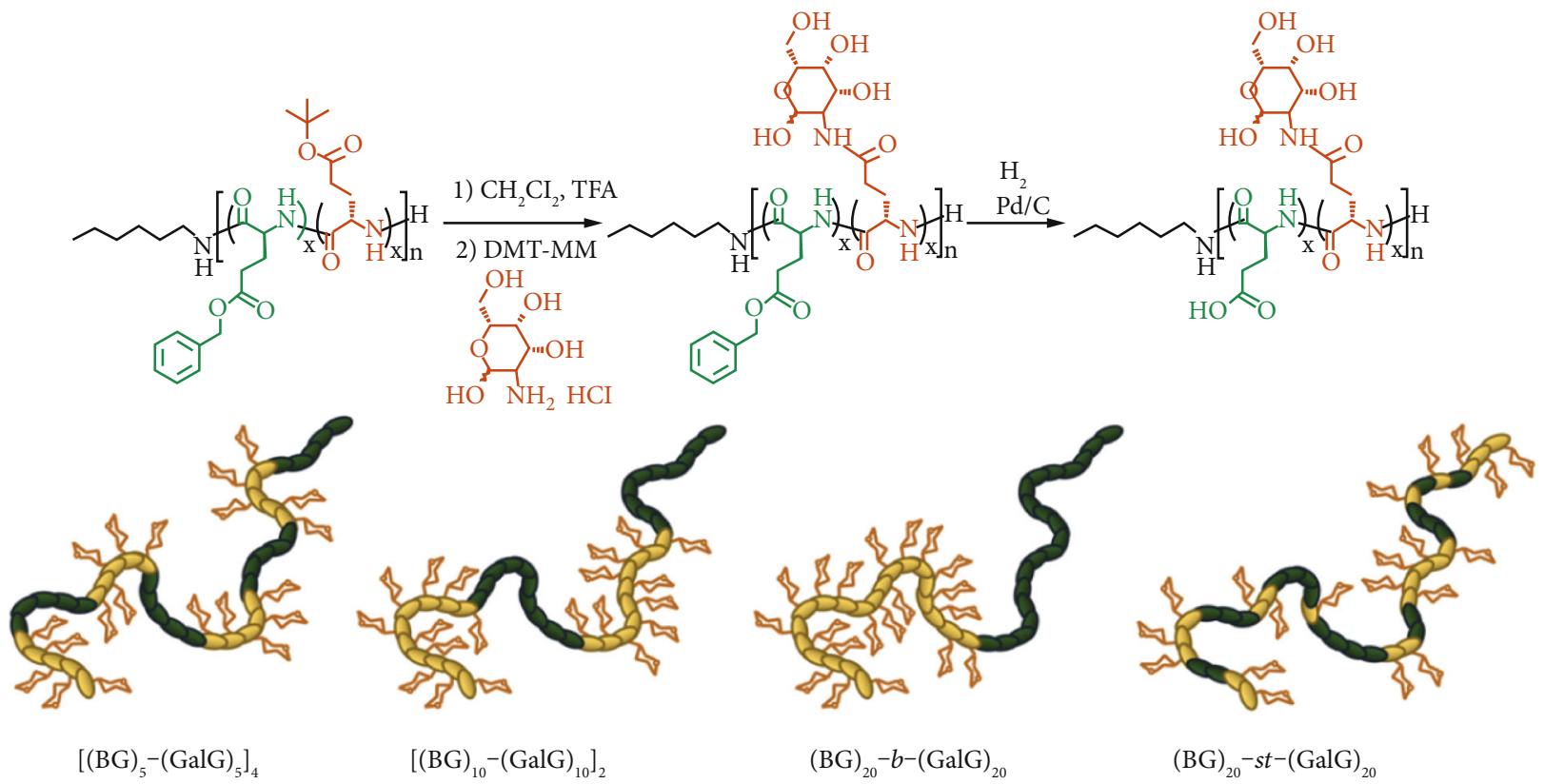

(a)

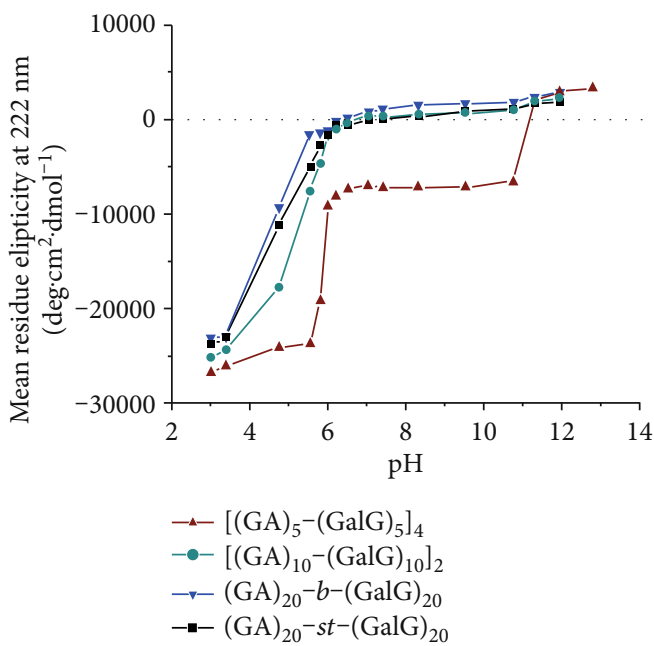

(b)

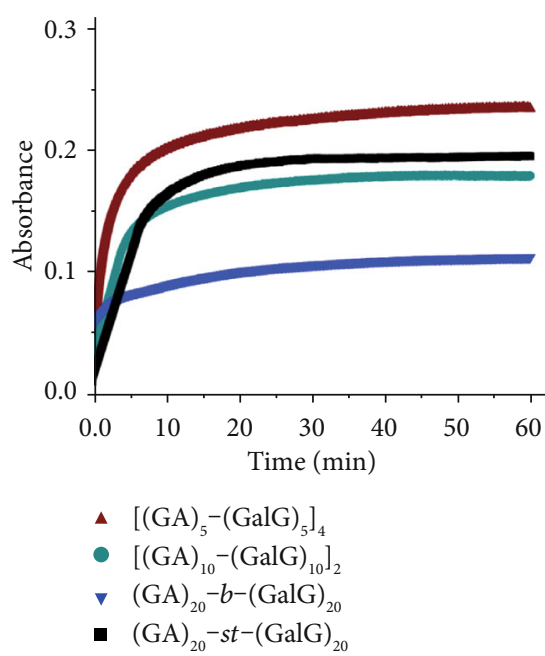

(c)

Figure 7: (a) Synthesis of glycopolypeptides with systematically varied defined primary structure. (b) Mean residue ellipticity at $222 \mathrm{~nm}$ vs. $\mathrm{pH}$ of block sequence-defined glycopolypeptides to show their secondary structures. (c) Absorbance vs. time after adding $50 \mu \mathrm{L}$ of glycopolypeptides $(1 \mathrm{mg} / \mathrm{mL})$ into $500 \mu \mathrm{L}$ of $\mathrm{RCA}_{120}(2 \mathrm{mg} / \mathrm{mL})$ (reprinted with permission from Ref. [86]; copyright (2017) American Chemical Society).

isolate, and purify biologically active substances, regulate cell adhesion, and induce cell proliferation and differentiation are still big challenges to be addressed.

As a future outlook, there are still huge spaces for further research and development of synthetic glycopolypeptides, including the following areas: (1) the preparation routes and the synthesis steps need to be simplified; accordingly, efficient purification strategies for the preparation of the synthetic functional glycopolypeptides need to be developed; (2) green monomer synthesis (using natural-based renewable building blocks along with onepot or cascade reaction) and controllable (e.g., metal-free, photocatalysis, organocatalysis, and enzyme catalysis) poly- merization processes and environmentally friendly reaction mediums (water, ionic liquid, etc.) need to be implemented; (3) "smart" monomer units (e.g., stimuli-responsive, biotargeting, and theranostic units) and monomer-matched polymerization methods need to be further developed; (4) the correlation between the physicochemical properties (hydrophilicity/phobicity, surface charge, and molecular topology) and self-assembly behavior of glycopolypeptides need to be clarified; (5) the biomedical applications as controllable/tunable nanoaggregates for drug/gene delivery, nano-/micromaterials as cell movement regulators, and bioprintable scaffolds for tissue engineering, as well as the biocompatibly soft matrix for neuron regeneration, 


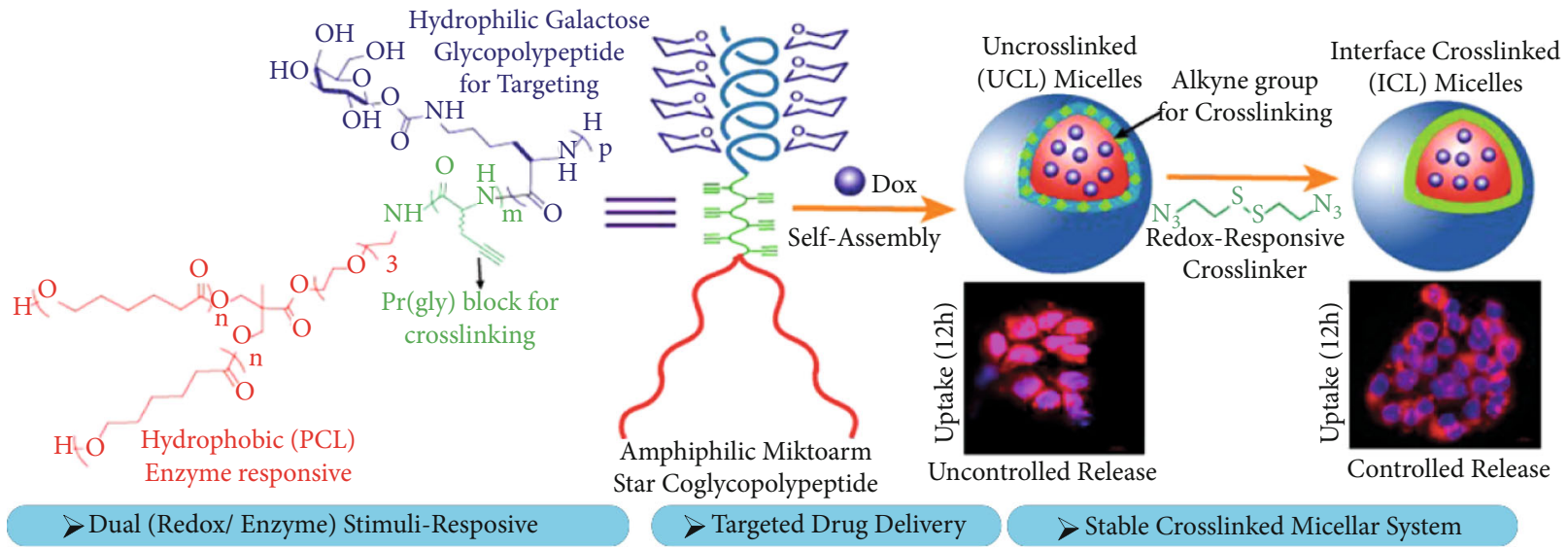

FIGURE 8: Synthesized amphiphilic star coglycopolypeptides and their self-assembly into uncrosslinked (UCL) and interface crosslinked (ICL) micelles for targeted and controlled drug delivery (reprinted with permission from Ref. [90]; copyright (2019) American Chemical Society).

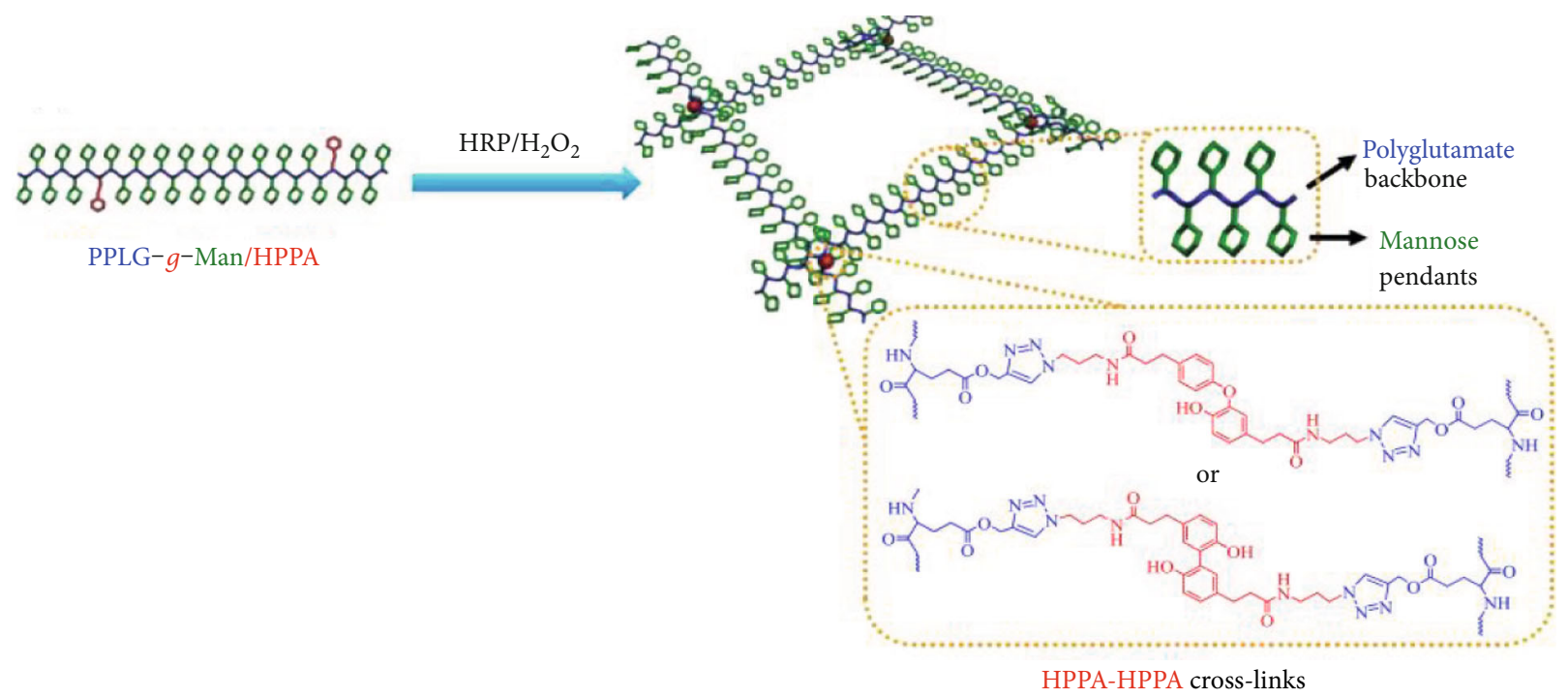

(a)
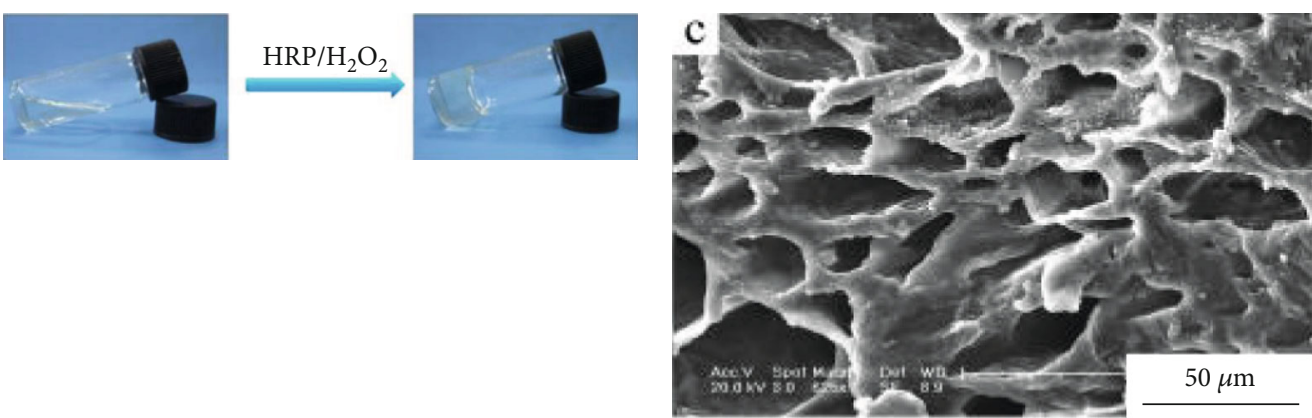

(b)

(c)

FIGURE 9: (a) Schematic illustration for the formation of crosslinking networks of PPLG- $g$-Man/HPPA hydrogels; (b) photographs of PPLG-

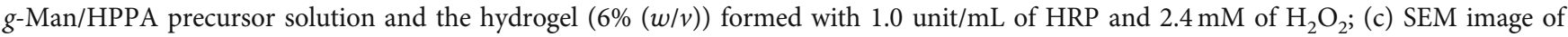
lyophilized PPLG-g-Man/HPPA hydrogels crosslinked with 1.0 unit/mL of $\mathrm{HRP}$ and $1.6 \mathrm{mM}$ of $\mathrm{H}_{2} \mathrm{O}_{2}$. The scale bar represents $50 \mathrm{~mm}$ (reprinted with permission from Ref. [94]; copyright (2013) American Chemical Society).

were greatly desired; and (6) notably, elucidating the glycopolymer-cell interaction mechanisms (e.g., cell recognition, receptor targeting, membrane channel modeling, signal transductions, and neuron signaling) is the key issue for rational design of glycopolymer-based biomaterials toward precise biomedicine. 
On this basis, we can expect that using the functional glycopolypeptide as an assembly element, further incorporating the controllable supramolecular assembly and/or the nanosynthesis method, more and more biomimetic glycopolypeptide nanoassemblies with high performance could be prepared towards future biomedical applications.

\section{Conflicts of Interest}

The authors declare that they have no conflicts of interest.

\section{Acknowledgments}

Dr. Zhao Wang thanks the foundation support from Natural Science Foundation of Jiangsu Province (Project No. BK20190113) and Jinling Institute of Technology (Project No: jit-b-201828). We appreciate ARDITI-Agência Regional para o Desenvolvimento da Investigação Tecnologia e Inovação, through the project M1420-01-0145-FEDER-000005Centro de Química da Madeira-CQM ${ }^{+}$(Madeira 14-20), ARDITI-2017-ISG-003, FCT-Fundação para a Ciência e a Tecnologia (Base Fund UIDB/00674/2020, CQM, Portuguese Government Funds), and project PROEQUI PRAM-Reforço do Investimento em Equipamentos e Infraestruturas Científicas na RAM (M1420-01-0145-FEDER-000008) for sponsorship.

\section{References}

[1] I. Canton, B. Ustbas, and S. P. Armes, "Galactosylated block copolymers: a versatile nano-based tool for effective intracellular drug delivery?," Therapeutic Delivery, vol. 5, no. 2, pp. 105107, 2014.

[2] X. Li and G. Chen, "Glycopolymer-based nanoparticles: synthesis and application," Polymer Chemistry, vol. 6, no. 9, pp. 1417-1430, 2015.

[3] G. Yilmaz and C. R. Becer, "Precision glycopolymers and their interactions with lectins," European Polymer Journal, vol. 49, no. 10, pp. 3046-3051, 2013.

[4] Y. Miura, "Design and synthesis of well-defined glycopolymers for the control of biological functionalities," Polymer Journal, vol. 44, no. 7, pp. 679-689, 2012.

[5] Z. Wang, T. Luo, R. Sheng, H. Li, J. Sun, and A. Cao, "Amphiphilic Diblock Terpolymer PMAgala-b-P(MAA-co-MAChol)s with Attached Galactose and Cholesterol Grafts and Their Intracellular pH-Responsive Doxorubicin Delivery," Biomacromolecules, vol. 17, no. 1, pp. 98-110, 2015.

[6] V. Ladmiral, E. Melia, and D. M. Haddleton, "Synthetic glycopolymers: an overview," European Polymer Journal, vol. 40, no. 3, pp. 431-449, 2004.

[7] S. Slavin, J. Burns, D. M. Haddleton, and C. R. Becer, "Synthesis of glycopolymers via click reactions," European Polymer Journal, vol. 47, no. 4, pp. 435-446, 2011.

[8] S. R. S. Ting, G. Chen, and M. H. Stenzel, "Synthesis of glycopolymers and their multivalent recognitions with lectins," Polymer Chemistry, vol. 1, no. 9, pp. 1392-1412, 2010.

[9] B. Voit and D. Appelhans, "Glycopolymers of various architectures-more than mimicking nature," Macromolecular Chemistry and Physics, vol. 211, no. 7, pp. 727-735, 2010.

[10] C. Cai, J. Lin, Y. Lu, Q. Zhang, and L. Wang, "Polypeptide selfassemblies: nanostructures and bioapplications," Chemical Society Reviews, vol. 45, no. 21, pp. 5985-6012, 2016.
[11] Y. Shen, X. Fu, W. Fu, and Z. Li, "Biodegradable stimuliresponsive polypeptide materials prepared by ring opening polymerization," Chemical Society Reviews, vol. 44, no. 3, pp. 612-622, 2015.

[12] R. A. Dwek, "Glycobiology: toward understanding the function of sugars," Chemical Reviews, vol. 96, no. 2, pp. 683-720, 1996.

[13] M. R. Pratt and C. R. Bertozzi, "Synthetic glycopeptides and glycoproteins as tools for biology," Chemical Society Reviews, vol. 34, no. 1, pp. 58-68, 2005.

[14] C. Bonduelle and S. Lecommandoux, "Synthetic Glycopolypeptides as Biomimetic Analogues of Natural Glycoproteins," Biomacromolecules, vol. 14, no. 9, pp. 2973-2983, 2013.

[15] K.-S. Krannig and H. Schlaad, "Emerging bioinspired polymers: glycopolypeptides," Soft Matter, vol. 10, no. 24, pp. 4228-4235, 2014.

[16] J. R. Kramer and T. J. Deming, "Recent advances in glycopolypeptide synthesis," Polymer Chemistry, vol. 5, no. 3, pp. 671-682, 2014.

[17] K. Aoi, K. Tsutsumiuchi, and M. Okada, "Glycopeptide Synthesis by an .alpha.-Amino Acid N-Carboxyanhydride (NCA) Method: Ring-Opening Polymerization of a SugarSubstituted NCA," Macromolecules, vol. 27, no. 3, pp. 875877, 1994.

[18] Z. Song, Z. Han, S. Lv et al., "Synthetic polypeptides: from polymer design to supramolecular assembly and biomedical application," Chemical Society Reviews, vol. 46, no. 21, pp. 6570-6599, 2017.

[19] J. Cheng and T. J. Deming, "Synthesis of polypeptides by ringopening polymerization of $\alpha$-amino acid N-carboxyanhydrides," Topics in Current Chemistry, vol. 310, pp. 1-26, 2012.

[20] E. Liarou, S. Varlas, D. Skoulas et al., "Smart polymersomes and hydrogels from polypeptide-based polymer systems through $\alpha$-amino acid $\mathrm{N}$-carboxyanhydride ring-opening polymerization. From chemistry to biomedical applications," Progress in Polymer Science, vol. 83, pp. 28-78, 2018.

[21] T. J. Deming, "Synthesis of side-chain modified polypeptides," Chemical Reviews, vol. 116, no. 3, pp. 786-808, 2016.

[22] G. K. Such, A. P. R. Johnston, K. Liang, and F. Caruso, "Synthesis and functionalization of nanoengineered materials using click chemistry," Progress in Polymer Science, vol. 37, no. 7, pp. 985-1003, 2012.

[23] S. Martens, J. O. Holloway, and F. E. Du Prez, "Click and clickinspired chemistry for the design of sequence-controlled polymers," Macromolecular Rapid Communications, vol. 38, no. 24, p. 1700469, 2017.

[24] D. Huang, Y. Liu, A. Qin, and B. Z. Tang, "Recent advances in alkyne-based click polymerizations," Polymer Chemistry, vol. 9, no. 21, pp. 2853-2867, 2018.

[25] C. Xiao, C. Zhao, P. He, Z. Tang, X. Chen, and X. Jing, "Facile synthesis of glycopolypeptides by combination of ringopening polymerization of an alkyne-substituted Ncarboxyanhydride and click "glycosylation"," Macromolecular Rapid Communications, vol. 31, no. 11, pp. 991-997, 2010.

[26] T. Borase, T. Ninjbadgar, A. Kapetanakis et al., "Stable Aqueous Dispersions of Glycopeptide-Grafted Selectably Functionalized Magnetic Nanoparticles," Angewandte Chemie (International ed. in English), vol. 52, no. 11, pp. 3164-3167, 2013.

[27] A. Kapetanakis and A. Heise, "Thermoresponsive glycopolypeptides with temperature controlled selective lectin binding properties," European Polymer Journal, vol. 69, pp. 483-489, 2015. 
[28] V. Dhaware, A. Y. Shaikh, M. Kar, S. Hotha, and S. Sen Gupta, "Synthesis and Self-assembly of Amphiphilic Homoglycopolypeptide," Langmuir : the ACS journal of surfaces and colloids, vol. 29, no. 19, pp. 5659-5667, 2013.

[29] J. Huang, G. Habraken, F. Audouin, and A. Heise, "Hydrolytically Stable Bioactive Synthetic Glycopeptide Homo- and Copolymers by Combination of NCA Polymerization and Click Reaction," Macromolecules, vol. 43, no. 14, pp. 60506057, 2010.

[30] C. Bonduelle, J. Huang, E. Ibarboure, A. Heise, and S. Lecommandoux, "Synthesis and self-assembly of "treelike" amphiphilic glycopolypeptides," Chemical Communications, vol. 48, no. 67, pp. 8353-8355, 2012.

[31] J. Huang, C. Bonduelle, J. Thévenot, S. Lecommandoux, and A. Heise, "Biologically Active Polymersomes from Amphiphilic Glycopeptides," Journal of the American Chemical Society, vol. 134, no. 1, pp. 119-122, 2012.

[32] H. Tang and D. Zhang, "General Route toward Side-ChainFunctionalized $\alpha$-Helical Polypeptides," Biomacromolecules, vol. 11, no. 6, pp. 1585-1592, 2010.

[33] A. J. Rhodes and T. J. Deming, "Soluble, clickable polypeptides from azide-containing N-carboxyanhydride monomers," ACS Macro Letters, vol. 2, no. 5, pp. 351-354, 2013.

[34] J. Sun and H. Schlaad, "Thiol-Ene Clickable Polypeptides," Macromolecules, vol. 43, no. 10, pp. 4445-4448, 2010.

[35] K.-S. Krannig and H. Schlaad, "pH-responsive bioactive glycopolypeptides with enhanced helicity and solubility in aqueous solution," Journal of the American Chemical Society, vol. 134, no. 45, pp. 18542-18545, 2012.

[36] K. S. Krannig, J. Huang, A. Heise, and H. Schlaad, "Photochemical thiol-yne functionalization of polypeptide scaffolds," Polymer Chemistry, vol. 4, no. 14, pp. 3981-3986, 2013.

[37] J. R. Kramer and T. J. Deming, "Preparation of Multifunctional and Multireactive Polypeptides via Methionine Alkylation," Biomacromolecules, vol. 13, no. 6, pp. 1719-1723, 2012.

[38] J. R. Kramer and T. J. Deming, "Reversible chemoselective tagging and functionalization of methionine containing peptides," Chemical Communications, vol. 49, no. 45, pp. 5144-5146, 2013.

[39] C. Gauche and S. Lecommandoux, "Versatile design of amphiphilic glycopolypeptides nanoparticles for lectin recognition," Polymer, vol. 107, pp. 474-484, 2016.

[40] H. K. Yang, J. F. Bao, L. Mo et al., "Bioreducible amphiphilic block copolymers based on PCL and glycopolypeptide as multifunctional theranostic nanocarriers for drug delivery and MR imaging," RSC Advances, vol. 7, no. 34, pp. 2109321106, 2017.

[41] E. Rüde, O. Westphal, E. Hurwitz, S. Fuchs, and M. Sela, "Synthesis and antigenic properties of sugar-polypeptide conjugates," Immunochemistry, vol. 3, no. 2, pp. 137-151, 1966.

[42] K. Tsutsumiuchi, K. Aoi, and M. Okada, "Synthesis of Polyoxazoline-(Glyco)peptide Block Copolymers by Ring-Opening Polymerization of (Sugar-Substituted) $\alpha$-Amino AcidNCarboxyanhydrides with Polyoxazoline Macroinitiators," Macromolecules, vol. 30, no. 14, pp. 4013-4017, 1997.

[43] J. R. Kramer and T. J. Deming, "Glycopolypeptides via living polymerization of Glycosylated-l-lysineN-Carboxyanhydrides," Journal of the American Chemical Society, vol. 132, no. 42, pp. 15068-15071, 2010.

[44] S. Das, N. Parekh, B. Mondal, and S. S. Gupta, "Controlled synthesis of end-functionalized mannose-6-phosphate glyco- polypeptides for lysosome targeting," ACS Macro Letters, vol. 5, no. 7, pp. 809-813, 2016.

[45] M. I. Gibson, G. J. Hunt, and N. R. Cameron, "Improved synthesis of O-linked, and first synthesis of S-linked, carbohydrate functionalised N-carboxyanhydrides (glycoNCAs)," Organic \& Biomolecular Chemistry, vol. 5, no. 17, pp. 2756-2757, 2007.

[46] K. Aoi, K. Tsutsumiuchi, A. Yamamoto, and M. Okada, "Globular carbohydrate macromolecule "sugar balls" 3. "Radialgrowth polymerization" of sugar-substituted $\alpha$-amino acid $\mathrm{N}$-carboxyanhydrides (glycoNCAs) with a dendritic initiator," Tetrahedron, vol. 53, no. 45, pp. 15415-15427, 1997.

[47] K. Aoi, K. Tsutsumiuchi, A. Yamamoto, and M. Okada, "Globular carbohydrate macromolecule "sugar balls", 2. Synthesis of mono(glycopeptide)-persubstituted dendrimers by polymer reaction with sugar-substituted $\alpha$-amino acid $\mathrm{N}$ carboxyanhydrides (glycoNCAs)," Macromolecular Rapid Communications, vol. 19, no. 1, pp. 5-9, 1998.

[48] E. Rüde and M. Meyer-Delius, "Synthesis of the $N$-carboxy- $\alpha$ amino acid anhydrides of several $O$-acetylated serine glycosides," Carbohydrate Research, vol. 8, no. 2, pp. 219-232, 1968.

[49] K. Aoi, K. Tsutsumiuchi, E. Aoki, and M. Okada, "First Synthesis of Glycopeptide Macromonomers and Graft-Type Sugar-Containing Polymers with Glycopeptide Side Chains," Macromolecules, vol. 29, no. 12, pp. 4456-4458, 1996.

[50] D. Pati, A. Y. Shaikh, S. Hotha, and S. S. Gupta, "Synthesis of glycopolypeptides by the ring opening polymerization of $\mathrm{O}$ glycosylated- $\alpha$-amino acid N-carboxyanhydride (NCA)," Polymer Chemistry, vol. 2, no. 4, pp. 805-811, 2011.

[51] D. Pati, A. Y. Shaikh, S. Das et al., "Controlled Synthesis ofOGlycopolypeptide Polymers and Their Molecular Recognition by Lectins," Biomacromolecules, vol. 13, no. 5, pp. $1287-$ 1295, 2012.

[52] T. Stöhr, A. R. Blaudszun, U. Steinfeld, and G. Wenz, "Synthesis of glycosylated peptides by NCA polymerization for recognition of human T-cells," Polymer Chemistry, vol. 2, no. 10, pp. 2239-2248, 2011.

[53] J. R. Kramer and T. J. Deming, "Glycopolypeptides with a redox-triggered helix-to-coil transition," Journal of the American Chemical Society, vol. 134, no. 9, pp. 4112-4115, 2012.

[54] K.-S. Krannig, A. Doriti, and H. Schlaad, "Facilitated Synthesis of Heterofunctional Glycopolypeptides," Macromolecules, vol. 47, no. 7, pp. 2536-2539, 2014.

[55] S. S.-S. Wang, S.-C. How, Y.-D. Chen, Y.-H. Tsai, and J.-S. Jan, "Bioactive saccharide-conjugated polypeptide micelles for acid-triggered doxorubicin delivery," Journal of Materials Chemistry B, vol. 3, no. 26, pp. 5220-5231, 2015.

[56] K. K. Upadhyay, J.-F. Le Meins, A. Misra et al., "Biomimetic Doxorubicin Loaded Polymersomes from Hyaluronan-blockPoly( $\gamma$-benzyl glutamate) Copolymers," Biomacromolecules, vol. 10, no. 10, pp. 2802-2808, 2009.

[57] H.-K. Yang and L.-M. Zhang, "New amphiphilic glycopolypeptide conjugate capable of self-assembly in water into reduction-sensitive micelles for triggered drug release," Materials Science \& Engineering. C, Materials for Biological Applications, vol. 41, pp. 36-41, 2014.

[58] C. Schatz, S. Louguet, J.-F. Le Meins, and S. Lecommandoux, "Polysaccharide-block-polypeptide Copolymer Vesicles: Towards Synthetic Viral Capsids," Angewandte Chemie International Edition, vol. 48, no. 14, pp. 2572-2575.

[59] Z. Wang, R. Sheng, T. Luo, J. Sun, and A. Cao, "Synthesis and self-assembly of diblock glycopolypeptide analogues 
PMAgala-b-PBLG as multifunctional biomaterials for protein recognition, drug delivery and hepatoma cell targeting," Polymer Chemistry, vol. 8, no. 2, pp. 472-484, 2017.

[60] K. K. Upadhyay, A. N. Bhatt, E. Castro et al., "In vitro and in vivo evaluation of docetaxel loaded biodegradable polymersomes," Macromolecular Bioscience, vol. 10, no. 5, pp. 503$512,2010$.

[61] C. Bonduelle, H. Oliveira, C. Gauche, J. Huang, A. Heise, and S. Lecommandoux, "Multivalent effect of glycopolypeptide based nanoparticles for galectin binding," Chemical Communications, vol. 52, no. 75, pp. 11251-11254, 2016.

[62] K. K. Upadhyay, A. K. Mishra, K. Chuttani et al., "The in vivo behavior and antitumor activity of doxorubicin-loaded poly $(\gamma$ benzyl l-glutamate)-block-hyaluronan polymersomes in Ehrlich ascites tumor-bearing BalB/c mice," Nanomedicine: Nanotechnology, Biology and Medicine, vol. 8, no. 1, pp. 71-80, 2012.

[63] K. K. Upadhyay, A. N. Bhatt, A. K. Mishra et al., "The intracellular drug delivery and anti tumor activity of doxorubicin loaded poly( $\gamma$-benzyl l-glutamate)-b-hyaluronan polymersomes," Biomaterials, vol. 31, no. 10, pp. 2882-2892, 2010.

[64] C. Feng, Y. Li, D. Yang, J. Hu, X. Zhang, and X. Huang, "Welldefined graft copolymers: from controlled synthesis to multipurpose applications," Chemical Society Reviews, vol. 40, no. 3, pp. 1282-1295, 2011.

[65] Y. Mai and A. Eisenberg, "Self-assembly of block copolymers," Chemical Society Reviews, vol. 41, no. 18, pp. 5969-5985, 2012.

[66] R. J. Williams, A. P. Dove, and R. K. O'Reilly, "Self-assembly of cyclic polymers," Polymer Chemistry, vol. 6, no. 16, pp. 29983008, 2015.

[67] C. Bonduelle, S. Mazzaferro, J. Huang, O. Lambert, A. Heise, and S. Lecommandoux, "Synthesis and self-assembly of branched glycopolypeptides: effect of topology and conformation," Faraday Discussions, vol. 166, pp. 137-150, 2013.

[68] A. R. Mohamed Wali, J. Zhou, S. Ma et al., "Tailoring the supramolecular structure of amphiphilic glycopolypeptide analogue toward liver targeted drug delivery systems," International Journal of Pharmaceutics, vol. 525, no. 1, pp. 191-202, 2017.

[69] L. Fu, C. Sun, and L. Yan, "Galactose Targeted pH-Responsive Copolymer Conjugated with Near Infrared Fluorescence Probe for Imaging of Intelligent Drug Delivery," ACS Applied Materials \& Interfaces, vol. 7, no. 3, pp. 2104-2115, 2015.

[70] D. Pranantyo, L. Q. Xu, Z. Hou, E. T. Kang, and M. B. ChanPark, "Increasing bacterial affinity and cytocompatibility with four-arm star glycopolymers and antimicrobial $\alpha$-polylysine," Polymer Chemistry, vol. 8, no. 21, pp. 3364-3373, 2017.

[71] S. Wong, M. S. Shim, and Y. J. Kwon, "Synthetically designed peptide-based biomaterials with stimuli-responsive and membrane-active properties for biomedical applications," $J$. Mater. Chem. B, vol. 2, no. 6, pp. 595-615, 2014.

[72] R. Wang, N. Xu, F. S. Du, and Z. C. Li, "Facile control of the self-assembled structures of polylysines having pendent mannose groups via $\mathrm{pH}$ and surfactant," Chemical Communications, vol. 46, no. 22, pp. 3902-3904, 2010.

[73] J. A. Hanson, Z. Li, and T. J. Deming, "Nonionic Block Copolypeptide Micelles Containing a Hydrophobicrac-Leucine Core," Macromolecules, vol. 43, no. 15, pp. 6268-6269, 2010.

[74] H. Matsui, M. Ueda, A. Makino, and S. Kimura, "Molecular assembly composed of a dendrimer template and block polypeptides through stereocomplex formation," Chemical Communications, vol. 48, no. 49, pp. 6181-6183, 2012.
[75] J. R. Kramer, A. R. Rodriguez, U.-J. Choe, D. T. Kamei, and T. J. Deming, "Glycopolypeptide conformations in bioactive block copolymer assemblies influence their nanoscale morphology," Soft Matter, vol. 9, no. 12, pp. 3389-3395, 2013.

[76] Y. Liu, Y. Zhang, Z. Wang et al., "Building nanowires from micelles: hierarchical self-assembly of alternating amphiphilic glycopolypeptide brushes with pendants of high-mannose glycodendron and oligophenylalanine," Journal of the American Chemical Society, vol. 138, no. 38, pp. 12387-12394, 2016.

[77] D. Pati, N. Kalva, S. Das, G. Kumaraswamy, S. S. Gupta, and A. V. Ambade, "Multiple topologies from glycopolypeptidedendron conjugate self-assembly: nanorods, micelles, and organogels," Journal of the American Chemical Society, vol. 134, no. 18, pp. 7796-7802, 2012.

[78] S. Das, D. K. Sharma, S. Chakrabarty, A. Chowdhury, and S. Sen Gupta, "Bioactive Polymersomes Self-Assembled from Amphiphilic PPO-GlycoPolypeptides: Synthesis, Characterization, and Dual-Dye Encapsulation," Langmuir, vol. 31, no. 11, pp. 3402-3412, 2015.

[79] D. Pati, S. Das, N. G. Patil et al., “Tunable Nanocarrier Morphologies from Glycopolypeptide-Based Amphiphilic Biocompatible Star Copolymers and Their Carbohydrate Specific Intracellular Delivery," Biomacromolecules, vol. 17, no. 2, pp. 466-475, 2016.

[80] J. J. Lundquist and E. J. Toone, "The cluster glycoside effect," Chemical Reviews, vol. 102, no. 2, pp. 555-578, 2002.

[81] M. Ambrosi, N. R. Cameron, and B. G. Davis, "Lectins: tools for the molecular understanding of the glycocode," Organic \& Biomolecular Chemistry, vol. 3, no. 9, pp. 1593-1608, 2005.

[82] A. E. Rodda, L. Meagher, D. R. Nisbet, and J. S. Forsythe, "Specific control of cell-material interactions: targeting cell receptors using ligand-functionalized polymer substrates," Progress in Polymer Science, vol. 39, no. 7, pp. 1312-1347, 2014.

[83] R. Sunasee, C. K. Adokoh, J. Darkwa, and R. Narain, “Therapeutic potential of carbohydrate-based polymeric and nanoparticle systems," Expert Opinion on Drug Delivery, vol. 11, no. 6, pp. 867-884, 2014.

[84] R. Mildner and H. Menzel, "Hydrophobic Spacers Enhance the Helicity and Lectin Binding of Synthetic, pH-Responsive Glycopolypeptides," Biomacromolecules, vol. 15, no. 12, pp. 45284533, 2014.

[85] M. Byrne, R. Mildner, H. Menzel, and A. Heise, "Glycosylated star polypeptides from NCA polymerization: selective binding as a function of degree of branching and glycosylation," Macromolecular Bioscience, vol. 15, no. 1, pp. 74-81, 2015.

[86] C. Lavilla, G. Yilmaz, V. Uzunova, R. Napier, C. R. Becer, and A. Heise, "Block-Sequence-Specific Glycopolypeptides with Selective Lectin Binding Properties," Biomacromolecules, vol. 18, no. 6, pp. 1928-1936, 2017.

[87] Y. Wang, Y. Fan, M. Zhang et al., "Glycopolypeptide nanocarriers based on dynamic covalent bonds for glucose dualresponsiveness and self-regulated release of insulin in diabetic rats," Biomacromolecules, vol. 21, no. 4, pp. 1507-1515, 2020.

[88] P. Li, J. Han, D. Li, J. Chen, W. Wang, and W. Xu, "Synthetic Glycopolypeptide Micelle for Targeted Drug Delivery to Hepatic Carcinoma," Polymers, vol. 10, no. 6, p. 611, 2018.

[89] J. Ding, C. Xiao, Y. Li et al., "Efficacious hepatoma-targeted nanomedicine self-assembled from galactopeptide and doxorubicin driven by two-stage physical interactions," Journal of Controlled Release, vol. 169, no. 3, pp. 193-203, 2013. 
[90] B. Pandey, N. G. Patil, G. S. Bhosle, A. V. Ambade, and S. S. Gupta, "Amphiphilic glycopolypeptide star copolymer-based cross-linked nanocarriers for targeted and dual-stimuliresponsive drug delivery," Bioconjugate Chemistry, vol. 30, no. 3, pp. 633-646, 2019.

[91] S. K. Mamidyala, S. Dutta, B. A. Chrunyk et al., "Glycomimetic ligands for the human asialoglycoprotein receptor," Journal of the American Chemical Society, vol. 134, no. 4, pp. 1978-1981, 2012.

[92] H.-F. Liang, T.-F. Yang, C.-T. Huang, M.-C. Chen, and H.W. Sung, "Preparation of nanoparticles composed of poly $(\gamma$ glutamic acid)-poly(lactide) block copolymers and evaluation of their uptake by HepG2 cells," Journal of Controlled Release, vol. 105, no. 3, pp. 213-225.

[93] H.-F. Liang, C.-T. Chen, S.-C. Chen et al., "Paclitaxel-loaded $\operatorname{poly}(\gamma$-glutamic acid)-poly(lactide) nanoparticles as a targeted drug delivery system for the treatment of liver cancer," Biomaterials, vol. 27, no. 9, pp. 2051-2059, 2006.

[94] Y. Cheng, C. He, C. Xiao et al., "Versatile Biofunctionalization of Polypeptide-Based Thermosensitive Hydrogels via Click Chemistry," Biomacromolecules, vol. 14, no. 2, pp. 468-475, 2013.

[95] K. Ren, C. He, C. Xiao, G. Li, and X. Chen, "Injectable glycopolypeptide hydrogels as biomimetic scaffolds for cartilage tissue engineering," Biomaterials, vol. 51, pp. 238-249, 2015.

[96] Y. Tachibana, N. Matsubara, F. Nakajima et al., "Efficient and versatile synthesis of mucin-like glycoprotein mimics," Tetrahedron, vol. 58, no. 51, pp. 10213-10224, 2002.

[97] G. Artigas, H. Hinou, F. Garcia-Martin, H.-J. Gabius, and S.I. Nishimura, "Synthetic Mucin-Like Glycopeptides as Versatile Tools to Measure Effects of Glycan Structure/Density/Position on the Interaction with Adhesion/Growth-Regulatory Galectins in Arrays," Chemistry - An Asian Journal, vol. 12, no. 1, pp. 159-167, 2017. 